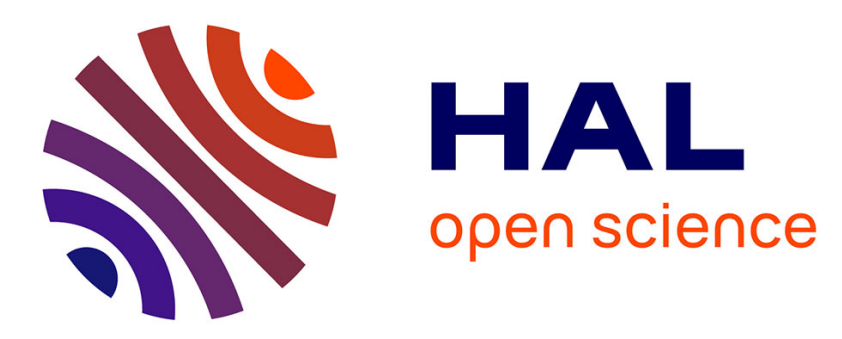

\title{
Modelling fish spatial dynamics and local density-dependence relationships : detection of patterns at a global scale
}

Orlane Anneville, Philippe Cury, Christophe Le Page, Jean Pierre Treuil

\section{To cite this version:}

Orlane Anneville, Philippe Cury, Christophe Le Page, Jean Pierre Treuil. Modelling fish spatial dynamics and local density-dependence relationships : detection of patterns at a global scale. Aquatic Living Resources, 1998, 11 (5), pp.305-314. 10.1016/S0990-7440(98)80001-6 . hal-02699140

\author{
HAL Id: hal-02699140 \\ https: / hal.inrae.fr/hal-02699140
}

Submitted on 1 Jun 2020

HAL is a multi-disciplinary open access archive for the deposit and dissemination of scientific research documents, whether they are published or not. The documents may come from teaching and research institutions in France or abroad, or from public or private research centers.
L'archive ouverte pluridisciplinaire HAL, est destinée au dépôt et à la diffusion de documents scientifiques de niveau recherche, publiés ou non, émanant des établissements d'enseignement et de recherche français ou étrangers, des laboratoires publics ou privés. 


\title{
Modelling fish spatial dynamics and local density-dependence relationships: detection of patterns at a global scale
}

\author{
Orlane Anneville ${ }^{(1 *)}$, Philippe Cury ${ }^{(2)}$, Christophe Le Page ${ }^{(3)}$, Jean Pierre Treuil ${ }^{(4)}$ \\ (1) Inra, Station d'hydrobiologie lacustre, 75, avenue de Corzent, BP 511, 74203 Thonon-les-Bains cedex, France. \\ (2) Orstom, Research Associate Sea Fisheries Research Institute, Private Bag X2, Rogge Bay, 8012 Cape Town, South Africa. \\ (3) Cirad, Campus de Baillarguet, BP 5035, 34032 Montpellier cedex 1, France. \\ (4) Orstom-laboratoire d'informatique appliquée, 32, avenue Henri-Varagnat, 93143 Bondy cedex, France.
}

Received April 16, 1998; accepted July 24, 1998.

\begin{abstract}
A model is used to explore whether local density-dependent recruitment relationships can be observed when considering a larger scale. A virtual population of spawners is tracked within an artificial environment composed of cells. Spawners can move from one cell to another on a spatial grid defined as a square lattice (lattice scale) made of $20 \times 20$ jointed hexagonal cells (local scale). Five spawner's behaviours are experimented successively: i) spawners stay in the same cell to spawn; ii) they move randomly towards one of the neighbouring cells; iii) they move towards the least populated neighbouring cell; iv) they move towards the most populated neighbouring cell; and v) they move randomly towards a neighbouring cell and then move towards the most populated neighbouring cell. When the migration of spawners is achieved, spawners reproduce only once, recruitment takes place and then they disappear. The recruitment is an event which occurs at a local scale: at the scale of the cell. Using Ricker's stock-recruitment relationship, in each cell the number of recruits is a function of the spawners. Random migrations and migrations towards the less populated cell allow a homogeneous distribution of the spawners throughout the lattice. Whereas in the three other cases, this distribution is not homogenised. The homogenisation of the lattice allows synchrony between local populations and then a stock-recruitment relationship is observable at the lattice scale. Simulations show that local density-dependence is not always detectable when considering large spatial scale. This result strengthens the idea that the choice of spatial scale is essential when studying stockrecruitment relationship. (C) Ifremer/Elsevier, Paris
\end{abstract}

Spatial dynamics / stock-recruitment relationship / Ricker's relationship / density dependence / spawning behaviour / individual based model

Résumé - Modélisation de dynamiques spatiales et de relations locales de densité-dépendance chez des populations de poissons : détections de caractéristiques à l'échelle globale. Le modèle élaboré pour cette étude a pour objectif de mettre en évidence l'importance de l'échelle spatiale dans la détection de relations de densité-dépendance chez des populations de poissons à savoir si des relations stock-recrutement existant à un niveau local peuvent également être observées à une plus grande échelle. Pour cela, une population de poissons géniteurs a été simulée dans un environnement artificiel composé de $20 \times 20$ cellules hexagonales, la cellule représente l'échelle locale et l'cnvironnement l'ćchelle globale. Cinq comportements migratoires ont été modélisés au cours de simulations successives : i) les géniteurs ne changent pas de cellule et se reproduisent dans la cellule où ils sont apparus ; ii) ils se déplacent vers une des huit cellules voisines ; leur choix étant aléatoire ; iii) ils se déplacent vers la cellule voisine la moins peuplée ; iv) ils se déplacent vers la cellule voisine la plus peuplée ; et v) ils se déplacent d'abord vers une des cellules voisines, puis vers la cellule voisine la plus peuplée. Quand tous les géniteurs ont migré, ils se reproduisent et meurent. Le recrutement a lieu à l'échelle locale. Dans chaque cellule, le nombre de recrues est déterminé par la mêtme fonction stock-recrutement de Ricker qui prend en considération le nombre de géniteurs présents dans la cellule au moment de la reproduction. Les migrations aléatoires et les migrations vers la cellule voisine la moins peuplée permettent d'avoir une distribution homogène de géniteurs dans l'environnement. Cette homogénéisation entre les cellules induit une synchronisation entre les différentes populations locales et la possibilité d'observer une relation stock-recrutement à l'échelle de l'environnement entier. En revanche, pour les trois autres modes de migration, les géniteurs ne sont pas répartis de façon homogène. Les simulations montrent que les relations de densité-dépendance définies à un niveau local ne sont pas toujours détectables à un niveau global. Ces résultats prouvent que l'étude d'un système passe en premier lieu par une bonne définition de l'échelle spatiale d'étude. Olfremer/Elsevier, Paris

Dynamiques spatiales / relation stock-recrutement / fonction de Ricker / densité-dépendance / stratégie de reproduction / modèle individu centré

* Corresponding author, e-mail: annevill@thonon.inra.fr 


\section{INTRODUCTION}

The concept of density dependence regulation appears to be the dominant contribution of the ecological theory, as it introduces stability and resilience in population dynamics [17]. In fishery science, the relationship between recruitment and spawning biomass is a subject of intense debate $[5,18]$ since it was formalised mathematically by Ricker [24] and Beverton and Holt [4]. According to this relationship, the number of recruits can be deduced from the number of spawners. This constitutes one of the most fundamental issues for the management of fish populations [19]. Many investigations attempt to model fish stock-recruitment relationship. Non-linear deterministic equations have been proposed to translate mathematically the effect of density dependent regulator mechanisms $[4,5,24,28]$. The Ricker stock-recruitment relationship is one of the most common mathematical models used in fisheries. This model attempts to describe the quantity of recruitment that is produced by the parental stock. His formulation produces a dome-shaped curve. As parental stock increases in size, the efficiency of recruitment (the number of recruits produced per spawning fish) decreases. This decline in recruitment for high stock values reflects density-dependent effects. In his interpretation, Ricker assumes that cannibalism is the main regulatory mechanisms within larval and juvenile populations: an increase in the mature stock not only increases the number of eggs laid in a given reproductive season, but it also decreases their rate of survival. Ricker's stock-recruitment relationship has the following mathematical formulation:

$$
R=\alpha S \exp ^{(-\beta S)}
$$

where $R$ is the number of recruits,

$S$ is the size of the stock of genitors (number of genitors),

$\alpha$ is the density-independent probability of survival,

$\beta$ is the coefficient of density-dependent mortality.

However such a relationship between recruits and spawning stock is rarely reflected in the body of fisheries' data: empirical data do not allow satisfactory adjustments and the detection of a density-dependence relationship is rarely obtained [6]. Several scientists also believe that there is no strong relationship between stock abundance and recruitment [13, 19, 34] and thus think that recruitment overfishing is almost impossible [15]. Many fisheries are then managed without consideration for maintaining a sustainable abundance of spawners [29]. Several investigations that deal with density-dependence regulation in biological populations (mostly insect populations) question this manner of analysing the data $[14,23,31]$. Turchin [31], for example, shows that an analysis that does not consider time lags is unsuitable to detect densitydependent regulation in populations that exhibit delayed density-dependent mechanisms. For insects populations, a wrong scale of study will not reveal the density-dependence relationship as it may be obscured by averaging over areas of heterogeneous population density [23]. And density-dependence is rarely detected in large scale studies, while the converse is true in smaller scale studies [23]. These observations stress the importance of studying spatial population structure when studying stock-recruitment relationship [23].

By simulating different spatial population structures (or spatial variances in density) and dynamics, we will focus on proper spatial scales to detect a densitydependent relationship. The purpose of this paper is to provide conclusive evidence that the choice of the spatial scale of study can be determinant in detecting a density-dependent relationship.

\section{METHODS}

\subsection{General modelling principles}

\subsubsection{The model}

The model implemented in $\mathrm{C}++$ is a hybrid model (we develop this point further in the general discussion). The model is made up of two components: an environmental and a biological unit. The environment is composed of a mosaic of potential spawning areas. It is represented by a homogeneous lattice divided into a number of jointed hexagonal cells (a hexagonal shape ensures better respect for spatial isotropy than a squared shape). We call the whole lattice 'the lattice scale' and a single cell 'the local scale'. The environmental component, controlled by simulation parameters is characterised by the total number of cells (number of cells in a line $\times$ number of cells in a column) and by the lattice boundaries; opposite edges may or not be considered to be joined to form a toroidal space. The biological component is made of a set of individual fish. The fish have two possible states: recruit and spawner. Spawners reproduce only once and locally in a cell. The new recruits become spawners, then they migrate. The life cycle of spawners is therefore made up of two stages: migration and reproduction. Only the first stage is described with an explicit individual-based approach. For reproduction, each spawner is identical and does not transmit any specific property to its offspring. In each cell, the result of the reproduction is expected to only depend on the number of spawners present in the cell. A Ricker's stock-recruitment relationship (appendix 1) is used in this study because it seems to be the most appropriate for regulating a wide range of number of spawners.

\subsubsection{Principle of the simulation}

At the beginning of the simulation, spawners are distributed randomly throughout the lattice. The local population is composed of spawners that are in a particular cell; the lattice population is composed of all 
the spawners that are in the lattice. During an iteration, the number of recruits in each cell is determined by the number of spawners present in the cell (local recruitment) using the Ricker's stock-recruitment equation. Spawners reproduce only once and then die. The recruits then become spawners and may migrate or stay in the cell according to the spawner's behaviour parameter considered. This ultimate phase completes an iteration and the simulation of the following iteration begins with spawning.

The duration of a simulation is determined by the number of spawning seasons. A simulated spawning season consists of four phases which are executed successively in one iteration (figure 1 ):

(i) Spawning and recruitment: in each cell, the number of recruit is density-dependent following Ricker's stock-recruitment relationship. The parameter, determining whether the dynamics are constant, cyclic or chaotic, is a simulation parameter and is constant for all cells during the entire simulation;

(ii) Death of spawners: when recruitment is achieved, all spawners die;

(iii) Maturation of recruits: in each cell, recruits become spawners;

(iv) Spawners behaviour: behaviour of spawners is a simulation parameter defined at the beginning of the simulation and is the same for the entire simulation and for all spawners.
Five different behaviours are considered. They are derived from reproductive strategies and ecological expectations:

(i) Homing strategy: successive generations reproduce at the same geographic location and spawners do not migrate;

(ii) Opportunistic strategy: the most common hypothesis postulates that an individual will try to select the environmental conditions that maximize its total reproductive output [21]. If environmental conditions have equal suitability then spawners do not have preferential spawning site, they may reproduce in any site. Each spawner migrates randomly towards one of the neighbouring cells; 'neighbouring cells' is used to indicate the environment composed by the current cell and by the six neighbourhood cells;

(iii) Density-dependent habitat selection: in field studies where population density varied sufficiently, it is common to observe differential utilisation of habitat depending on population size [16]. As a consequence, the 'density-dependent habitat selection' states that the population size and the local density are important factors that influence the choice of a habitat and hence the relative distribution of the population among habitats. Habitats may be ordered in terms of basic 'suitability' [7]. Due to density-dependent effects such as the increasing density of individuals in a habitat, the realised suitability decreases. In an ideal free distribution', all individuals choose the most suitable habitat. For this scenario, an ideal free distribution is simu-
Figure 1. Individual based model flow chart. Each simulation is characterised by parameters which are defined at the beginning of the simulation. $\alpha$ : The parameter $\alpha$ of Ricker's stock-recruitment relationship (appendix 1); nb-seasons: the number of iterations; nb-lines: the number of cells in a column; nb-columns: the number of cells in a line; nb-genitors: the initial number of genitors; behaviours: the kind of genitors' behaviour (one behaviour without migration and four behaviours with different kinds of migrations). The number of spawning seasons (number of iterations) determines the duration of a simulation. A spawning scason consists of four phases which are executed successively. The portions within the dashed lines depict the fish behaviours during a spawning season.

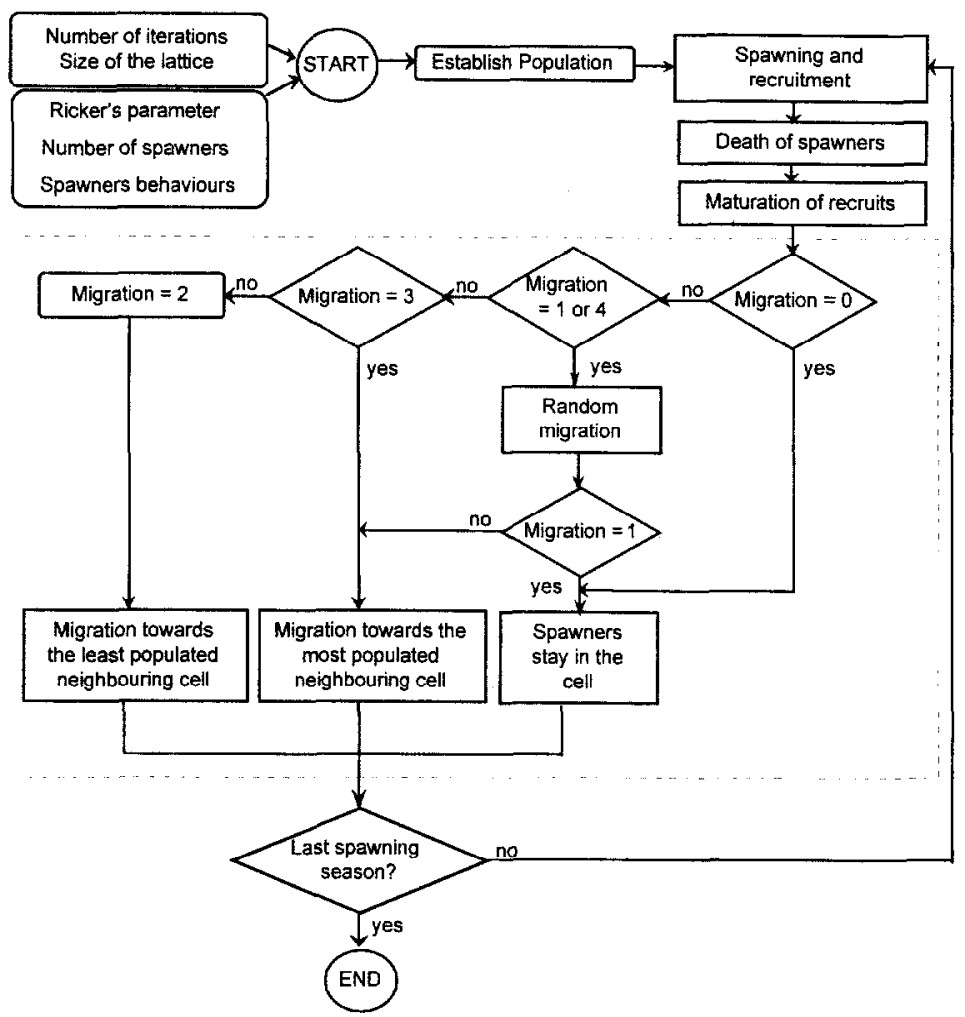


Table I. Results of simulations in a $20 \times 20$ closed lattice and for a duration of 200 reproductive seasons. Initial lattice density is equal to 5 , $\beta=0.01$ and $\alpha=2.72,11.5$ or 17.71 which induces a theoretical local dynamic constant, cyclic or chaotic, respectively. For each behaviour and $\alpha$ value tested, the system settles into a characteristic dynamical behaviour. The dynamics of variations has been determined for the entire simulation by the calculation of the Lyapunov exponent $[2,3,32]$.

\begin{tabular}{|c|c|c|c|c|}
\hline \multirow{2}{*}{$\begin{array}{l}\text { Parameters } \\
\text { Behaviours }\end{array}$} & \multicolumn{3}{|c|}{ Dynamics at the lattice scale } & \multirow[t]{2}{*}{ Synchronisation of cells } \\
\hline & $\begin{array}{c}\text { Theoretical local } \\
\text { dynamics }\end{array}$ & $\begin{array}{l}\text { Magnitude of lattice } \\
\text { density variations }\end{array}$ & $\begin{array}{l}\text { Dynamic } \\
\text { of variations }\end{array}$ & \\
\hline No migration & $\begin{array}{l}\text { Constant } \\
\text { Cyclic } \\
\text { Chaotic }\end{array}$ & $\begin{array}{l}\text { Nil } \\
\text { Strong or nil } \\
\text { Medium }\end{array}$ & $\begin{array}{l}\text { Non chaotic } \\
\text { Non chaotic } \\
\text { Non chaotic }\end{array}$ & $\begin{array}{l}\text { Synchronous } \\
\text { Synchronous } \\
\text { Non synchronous }\end{array}$ \\
\hline Random migration & $\begin{array}{l}\text { Constant } \\
\text { Cyclic } \\
\text { Chaotic }\end{array}$ & $\begin{array}{l}\text { Nil } \\
\text { Strong } \\
\text { Strung }\end{array}$ & $\begin{array}{l}\text { Non chaotic } \\
\text { Non chaotic } \\
\text { Chaotic }\end{array}$ & $\begin{array}{l}\text { Synchronous } \\
\text { Synchronous } \\
\text { Almost synchronous }\end{array}$ \\
\hline $\begin{array}{l}\text { Migration towards } \\
\text { the least populated } \\
\text { neighbouring cell }\end{array}$ & $\begin{array}{l}\text { Constant } \\
\text { Cyclic } \\
\text { Chaotic }\end{array}$ & $\begin{array}{l}\text { Almost nil } \\
\text { Strong } \\
\text { Strong }\end{array}$ & $\begin{array}{l}\text { Non chaotic } \\
\text { Non chaotic } \\
\text { Chaotic }\end{array}$ & $\begin{array}{l}\text { Synchronous } \\
\text { Synchronous } \\
\text { Almost synchronous }\end{array}$ \\
\hline Mixed migration & $\begin{array}{l}\text { Constant } \\
\text { Cyclic } \\
\text { Chaotic }\end{array}$ & $\begin{array}{l}\text { Very low } \\
\text { Low } \\
\text { Low }\end{array}$ & $\begin{array}{l}\text { Chaotic } \\
\text { Chaotic } \\
\text { Chaotic }\end{array}$ & $\begin{array}{l}\text { Non synchronous } \\
\text { Non synchronous } \\
\text { Non synchronous }\end{array}$ \\
\hline
\end{tabular}

lated, each spawner migrates towards the least populated neighbouring cell which is supposed to be the most suitable habitat. If there are more than one, the destination is chosen randomly among these cells;

(iv) Schooling strategy: schooling is common in fish population, particularly for pelagic fish. Fish gather by reciprocal attraction governed by stimuli. Each spawner migrates towards the most populated neighbouring cell. If there are more than one, the destination is chosen randomly among these cells;

(v) Dispersion and concentration: each spawner migrates a first time randomly towards one of the neighbouring cell and then migrates towards the most populated neighbouring cell. This behaviour is a combination of behaviour (ii) and (iv). The first movement of random dispersion allows a redistribution and a mixing of the population throughout the lattice. The second step simulates the phenomena of looking for a reproduction area.

Movements are asynchronous. Spawners are organised as a list of individuals. Each spawner is considered successively. An individual chooses a destination cell and migrates towards this cell. This implies that the choice of each spawner's destination is influenced by the choice of the preceding one.

\subsection{Simulations}

The simulations are divided in two different ways. The first simulations for each spawners' behaviour were realised with three deterministic dynamics: damped oscillations converge to a stable equilibrium point, become cyclic of period 2 or chaotic (respectively: $\alpha=2.72,11.55$ and 17.71). To allow a comparative analysis, the lattice structure and the number of iterations were the same: $20 \times 20$ closed lattice and 200 iterations. The lattice was large enough to inhibit the edge effect and to notice the impact of the spatial scale. The number of iterations has been chosen such that they are long enough to allow the colonisation of the entire environment and to allow the establishment of the characteristic lattice of the population's dynamical behaviour.

For comparative purpose, we have focused on testing the importance of spatial and temporal scale by changing the size of the lattice $(5 \times 5$ lattice) and the number of iterations (5000 iterations). Simulations have been done for $\alpha=17.71$ (chaotic dynamic) with migrations towards the least populated neighbouring cell.

\section{RESULTS}

When movements are introduced in a lattice composed of $20 \times 20$ cells, each cell becomes occupied by spawners and the system settles into a characteristic dynamical behaviour. Every behaviour has a resulting lattice dynamic that is similar to that obtained with other behaviours. Results of these simulations are presented in table $I$.

\subsection{Simulation 1}

\subsubsection{Behaviour without migration and behaviour with migration towards the most populated neighbouring cell}

Individuals gathering in the most populated cells induce the formation of isolated local populations whose dynamics are independent of each other. This behaviour is quite similar to a system made up of isolated populations (without migration).

- Simulation with $\alpha=2.72$. All local densities tend towards a fixed density equal to $\ln \alpha / 0.01$. At the lat- 
Figure 2. Example of behaviour without movement: 200 reproductive seasons, $20 \times 20$ cells, initial lattice density equal to $5, \beta=0.01$ and $\alpha=17.71$. a) Graph of synchronisation. Local density of each cell changes independently of the other, cells are not synchronised. b) Graph of lattice stock recruitment-relationship. Scattered points are localised in a reduced space.
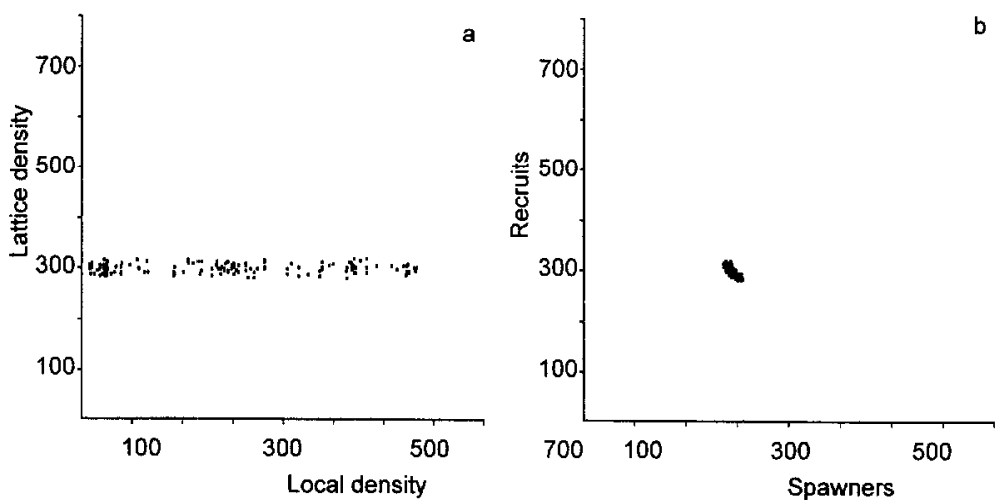

tice scale, the dynamic is stable and the lattice density tends towards an equilibrium value.

- Simulation with $\alpha=11.55$. The dynamic of each cell is similar. All local densities alternate in a stable 2point cycle. Local dynamics are then synchronised. The term 'synchronisation' is used to indicate that there is a correlation between local dynamics. This correlation does not exclude a lag: synchronised cells are either in phase or in opposite phase. This synchronisation induces, at the lattice scale, a stable cyclic oscillation between two density points. Values of the two fixed points depend on the number of cells which are in phase and in opposite phase. If the number of cells in phase is equal to the number of cells in opposite phase, the lattice density tends towards a constant point.

- Simulation with $\alpha=17.71$. Local dynamics are chaotic, they can not be synchronised: the graph of synchronisation reveals that the local density of each cell changes independently of the others (figure 2a). When plotting the local number of recruits for each cell during an iteration, graphs show that each cell gives a different number of recruits. The total density of recruits can not be deduced from Ricker's relationship; it represents the sum of local densities resulting from the Ricker relationship. Then, the stock-recruitment graph shows scattered data points localised in a reduced space (figure $2 \mathrm{~b}$ ).

\subsubsection{Behaviour with random migrations and migrations towards the least populated neighbouring cell}

Random movements induce a homogenisation of the population: they allow synchronisation between local dynamics and the emergence of a Ricker's stockrecruitment relationship at the scale of the lattice. It is even more obvious for behaviour with movements towards the least populated neighbouring cell.

- Simulation with $\alpha=2.72$. The lattice is uniform; at equilibrium, all local populations reach the same density. Therefore if a spawner leaves a cell, it is immediately replaced by an immigrant from a neighbouring cell. This phenomenon allows a lattice homogenisation. Then the dynamics at the lattice scale is similar to the one defined by Ricker's stock-recruitment relationship at the cell level and the lattice density tends towards a fixed point equals to $\ln \alpha / 0.01$.

- Simulation with $\alpha=11.55$. Migrations allow a lattice homogenisation and population dynamics at the lattice scale is also cyclic of period 2.

- Simulation with $\alpha=17.71$. When the system is stabilised, the graph of instantaneous stock-recruitment relationship shows that each cell has almost the same local spawner density and thus produces almost the same number of recruits. Migrations allow a synchronisation between cells (figure 3a). The lattice density seems to oscillate between two attractive areas (figure 3b), and the values of the Lyapunov's exponent reveal a chaotic dynamic (appendix 2).

\subsubsection{Behaviour with mixed movement}

Migrations do not allow a lattice homogenisation, thus cells can not be synchronised and the dynamic at the lattice scale does not look like a Ricker's stockrecruitment relationship. In comparison with our previous results, this behaviour presents two particularities:

- the lattice density fluctuations are smaller than density fluctuations of previous simulations and at the lattice scale, there is a regulatory phenomenon which does not appear for the previous simulations;

- whatever the $\alpha$ value, the Lyapunov's exponent value (appendix 2) shows that the dynamic at the lattice scale is chaotic; lattice dynamic properties are not a function of the local $\alpha$.

\subsection{Simulation 2}

A comparative study of behaviour with migrations towards the least populated neighbourhood cell shows that the detection of a stock-recruitment relationship is sensitive to the number of reproductive scasons and to the size of the lattice (figures 3-6).

\subsubsection{From 200 to 5000 reproductive seasons in a $20 \times 20$ lattice, $\alpha=17.71$ (chaotic)}

Values of the two attractive areas observed for 200 reproductive seasons are shifting during the simu- 

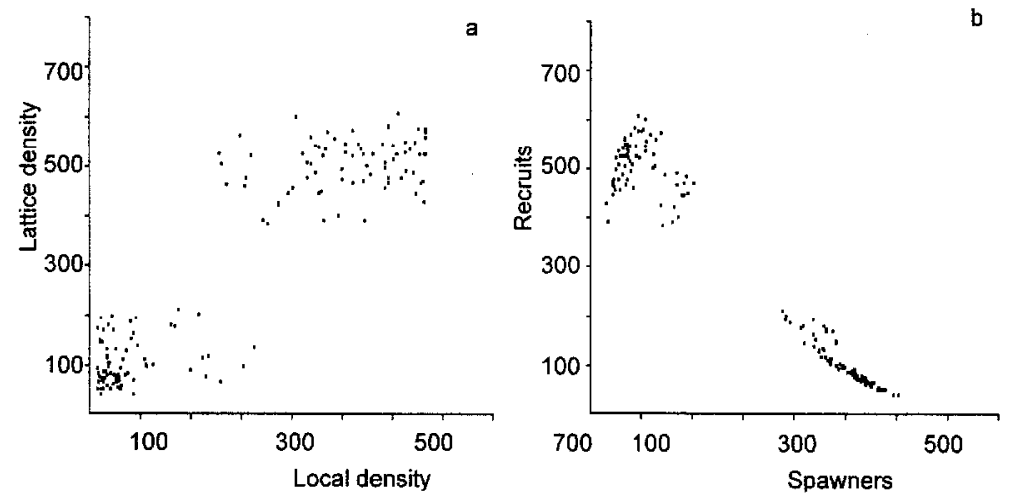

Figure 3. Example of behaviour with movement towards the least populated neighbourhood cell: 200 reproductive seasons, $20 \times 20$ cells, initial lattice density equal to $5, \beta=0.01$ and $\alpha=17.71$. a) Graph of synchronisation. There is a synchronisation between cells; each cell has almost the same local spawner density and thus produces almost the same number of recruits. b) Graph of lattice stock recruitment-relationship. The lattice density oscillates between two attractive areas.
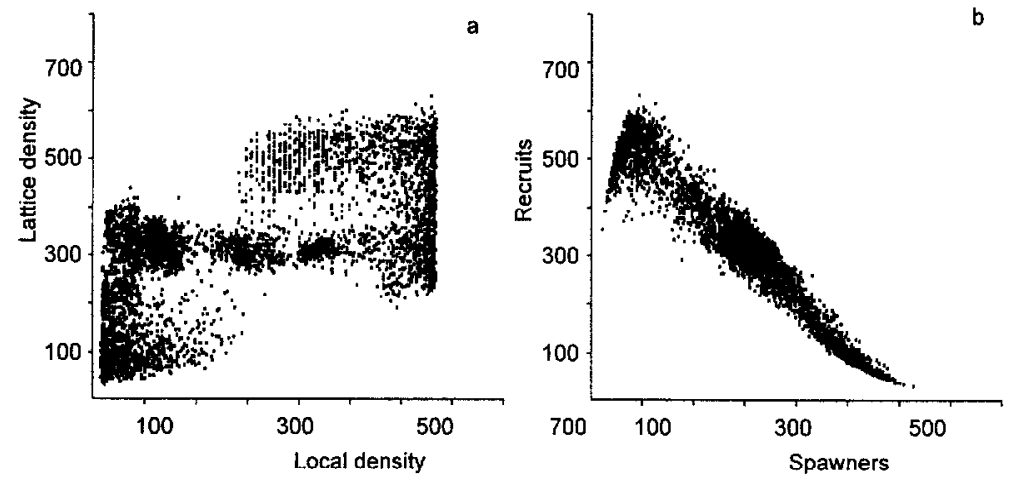

Figure 4. Example of behaviour with movement towards the least populated neighbourhood cell: 5000 reproductive seasons, $20 \times 20$ cells, initial lattice density equal to $5, \beta=0.01$ and $\alpha=17.71$. a) Craph of synchronisation. There is a small desynchronisation between some cells. b) Graph of lattice stock-recruitment relationship. The values of the two altraclive areas are shifting during the simulation and a Ricker's stock-recruitment relationship appears at the lattice scale.

lation (figures 3, 4). For 5000 reproductive seasons, we observed a relationship which is similar to a Ricker's stock-recruitment relationship. In the longterm, the apparent oscillation disappears and a global chaotic behaviour is observed. The stock-recruitment relationship at a lattice scale becomes more apparent with increasing simulation time. However, the curve presents differences compared to the curve of the local Ricker's relationship:

- It is thick;

- The extreme values of density are missing.

We hypothesised that migrations allow the conservation of a synchronisation between local chaotic dynamics. But they are slightly desynchronised (figure 4a). This desynchronisation, which evolved with time, is not strong enough to prevent, on the long-term, the emergence of a Ricker's stock-recruitment relationship (figure $4 \mathrm{~b}$ ). The desynchronisation maintains differences of density between cells. These differences between local densities are responsible for the observed particularities (thick and truncated) of the curve (we will discuss this observation later).

\subsubsection{From 200 to 5000 reproductive seasons in a $5 \times 5$ lattice, $\alpha=17.71$ (chaotic)}

If the spatial grid is small (lattice $5 \times 5$ ), a Ricker's stock-recruitment relationship appears for 200 reproductive seasons (figure 5b). After 5000 reproductive seasons, this relationship is always clear (no thickness, complete) and looks similar to the local one (figure 6b). Because the lattice is made up of a few cells, the migrations allow a rapid and strong synchronisation between all the cells, which can be maintain over time (figures 5a and 6a). A time scale of 200 iterations is enough to observe a lattice dynamic similar to the local ones and then the lattice dynamic exhibits a chaotic behaviour.

\section{DISCUSSION}

\subsection{The model}

Recently, there has been a growing interest in the importance of considering space in animal population dynamics $[8-12,20,25-27,30]$. One of the key questions was to understand the effects of movements between spatially separated populations. Using an individual based approach seems to be a constructive way to simulate specific individual behaviour and it allows a better understanding of the dynamics of the entire system. However, in this study, we have defined an hypothesis on the cnvironment and fish behaviour (identical reproductive local behaviour) which allows the simplification of the computation: conceptually spawners are always considered as individuals but reproduction is modelled at a local population level while migration is considered at an individual level. The hypothesis on migrations allows the comparison of our model with a stochastic matrix framework :

$$
S_{t+1}=R\left(S_{t}\right)
$$


Figure 5. Example of behaviour with movement towards the least populated neighbourhood cell: 200 reproductive seasons, $5 \times 5$ cells, initial lattice density equal to $5, \beta=0.01$ and $\alpha=17.71$. a) Graph of synchronisation. The cells become rapidly synchronised. b) Graph of lattice stock-recruitment relationship. At the lattice scale, a Ricker's stock-recruitment relationship appears.
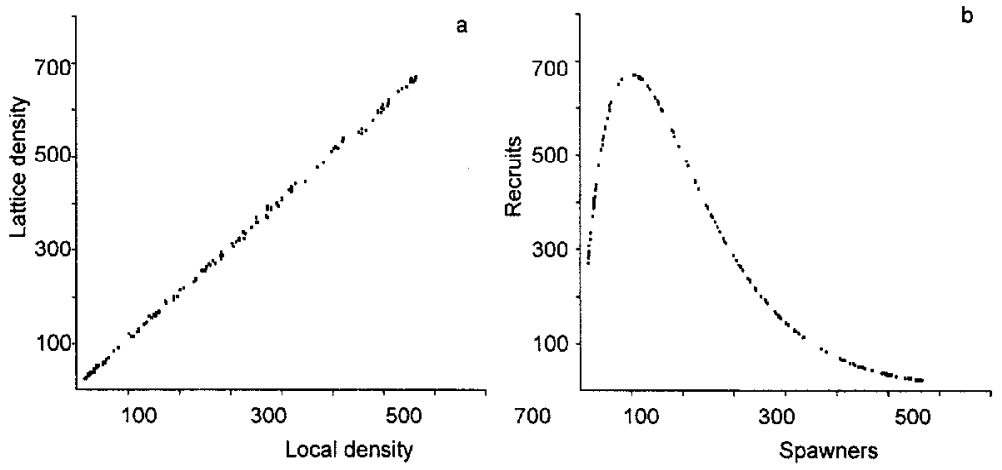

Figure 6. Example of behaviour with movement towards the least populated neighbourhood cell: 5000 reproductive seasons, $5 \times 5$ cells, initial lattice density equal to $5, \beta=0.01$ and $\alpha=17.71$, a) Graph of synchronisation. There is a synchronisation between all cells. b) Graph of lattice stock-recruitment relationship. At the lattice scale, a stock-recruitment relationship appears and is similar to the local one.
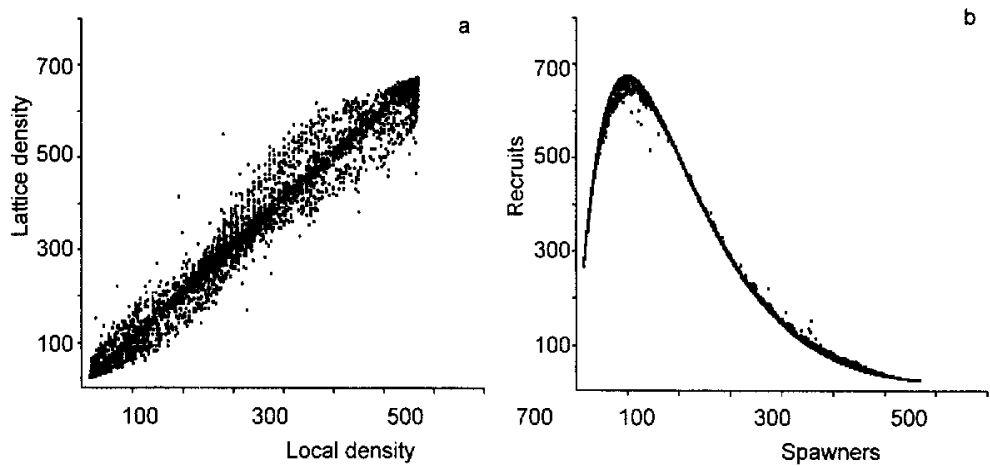

with $S_{t}:$ the vector of the number of spawners in each cell at time $t$ before reproduction,

$S_{t}^{\prime}:$ the vector of the number of recruits in each cell,

$S_{t+1}$ : the vector of the number of spawners in each cell at time $t+1$ after migrations.

Each component of $S_{t}^{\prime}$ is deduced from the corresponding component of $S_{t}$ by Ricker's function. The relation between $S_{t+1}$ and $S_{t}$ depends on the experimental behaviour:

- if there is no migration or migration towards the most populated neighbouring cell, after a short period: $S_{t+1}=S_{i}$

- for random migrations: $S_{t+1}=(M+\varepsilon) S_{t} \cdot M_{i j}$ takes the value 0 or $1 / 9$ in function of the ranges of the cells $i$ and $j$;

- for migrations towards the least populated neighbouring cell and mixed movements, the process leading from $S_{t}$ to $S_{t+1}$ can not be written within a matrix where $M$ is independent of $S$. But in the first case, it is obvious that the process tends to homogenise the number of spawners in the cells. In contrast, in the second case, the dynamic of $S_{t}$ has no stable attractor.

\subsection{Comments on studied behaviours and results}

The values $\alpha$ and $\beta$ have been chosen to allow a systematic exploration of the different dynamical behav- iours which are generated by Ricker's equation. The purpose was more to test each behaviour which can be produced by the relationship than applying a fixed value which has been found to be characteristic for a given population.

The lattice may be viewed as an oceanic area where each cell is a potential spawning area in which larvae and juveniles grow until recruitment. The length of individual paths is then representative of the distance between natal and reproductive sites. Mechanisms of regulation and limitation involved in density-dependence concept occur at a local spatial scale, i.e. the local population where a regulation by mechanisms such as competition and cannibalism do exist. As it was emphasized by Ray and Hasting [23], the detection of such a relationship, which occurred at a defined scale, requires an appropriate spatial scale when studied. When the spatial scale of study is large compared to the spatial scale on which regulatory mechanism acts, then local density heterogeneity smooth the population oscillations and do not allow to detect a density-dependence relationship.

\subsubsection{Behaviour without migration}

In the first scenario, the distance between the natal and the reproductive cell is nil: individuals reproduce in their native site. It is a simulation that may represent, in a sense, natal homing. If there are no exchanges of spawners between spawning sites, simulations of sta- 
ble local dynamics lead to an entire system with stable properties. On the other hand, as it has been underlined by Wilson et al. [33], the sum of local chaotic dynamics leads to the stability of the entire population compared with the dynamics of local populations. We can assert that the smooth oscillations observed at the lattice scale are a statistical consequence. Even if, in each of these sites, the number of recruits is locally determined by Ricker's relationship, at a larger scale, such a relationship is not observed. The lattice does not seem to be regulated by density-dependent mechanisms even if this is the case in each individual cell.

\subsubsection{Behaviour with migrations}

Investigations where individuals move randomly through their neighbourhood may stand for a situation in which individuals do not have determined spawning sites. There is a mixing between local populations and we have shown that these movements have a homogenising role. They allow synchrony to develop between local populations. This phenomenon is more obvious with migrations towards the least populated neighbouring cell. It gives a lattice dynamic which is the same as the local one. And even at the lattice level, a stockrecruitment relationship is detectable. Nevertheless such a relationship is more obvious if the number of local populations is small because a synchronisation between populations is more likely to establish itself if there are few populations. The difficulty of detecting a complete stock-recruitment relationship, when considering a large scale, may be linked to the differences of density between each local population. It seems that maximal values of the average density are smaller than those of the local ones: at a large scale, the resulting relationship seems to be shrunk in a smaller range of density compared to the local ones. This observation may be linked to the divergence of density between local cells: the higher the difference between local densities is, the smaller the range of density values.

Movements towards the least populated neighbouring cell do not seem ecologically realistic. Individuals act to limit competition (for space, food, etc.) but to reproduce, they generally concentrate in favourable environments. This behaviour can be compared with the last investigated (mixed movements) in which there is a first phase of dispersal after recruitment and a second phase of concentration for reproduction. In this case, movements do not allow a synchronisation between local populations and we can not detect a stock-recruitment relationship at a lattice scale. Nevertheless as the lattice density is almost stable, we notice the presence of a lattice population regulation phenomenon. The regulatory properties of the local stockrecruitment relationship also act at the lattice population scale.

When movements are introduced, we have shown that the equilibrium stability properties of local sys- tems remain entirely unaffected by random and density-dependent migrations as environment is entirely uniform (at equilibrium, all local populations have the same density). As it has been argued by Rohani et al. [25], when dispersal to and from local populations is in balance it does not alter the equilibrium properties of local populations. However, simulations with mixed behaviours show that any movements can induce an unstable lattice dynamic. These results match the observations which assume that in some cases, dispersal can have destabilising consequences on the entire system. Highly asymmetric dispersal in predator-prey interactions [1] and in host-parasite interaction [22] can have a destabilising effect on the population, even if at a local scale, populations are stable. Ruxton [27] shows that if the migration rate is important enough, density-dependent migrations may have a destabilising effect. But the majority of investigations confirm that in a wide range of situations the strength of coupling between neighbours, and the size of the environment do not have a substantial influence on the local stability $[25,26]$. Local coupling have been shown to affect qualitative features of unstable dynamics [26]. Concluding that migrations mostly do not affect local stability does not mean that migrations have no consequences on the structure and behaviour of the whole system. For example, such a migration can enhance persistence of the whole population despite probability of local extinction [11]. By strengthening the idea that individual movement behaviours have consequences on the dynamics, we have shown that the scales employed can strongly influence the detection of populations patterns and processes. And migrations between local populations may strongly influence results.

\section{CONCLUSION}

Observation of population dynamics can be influenced by the spatial scale of the study. Populations can be, for example, regulated by local density-dependence regulatory phenomena which become undetectable at the scale of the entire population. Stock-recruitment relationship can not always be observable with a classical stock-recruitment relationship, but this does not mean that it does not exist. Thus, even if stock-recruitment relationship is not observable at the population scale, spawner abundance should not be ignored when managing fish population.

These observations can be used in domains other than fisheries science. Nevertheless, the problems discussed here, such as migratory behaviour and stockrecruitment relationship, are very important to understand population dynamics and it requires further attention in the future. 


\section{Acknowledgement}

This research was conducted as part of the GIP 'Hydrosystèmes' through its theme 'Fish and its environment'.

\section{REFERENCES}

[1] Allen J.C., Mathematical models of species interactions in time and space, Am. Nat. 109 (1975) 319-342.

[2] Alligood K.T, Sauer T.D, Yorke J.A., Chaos: An introduction to dynamical systems, Springer, 1996, $601 \mathrm{p}$.

[3] Bergé P., L'ordre dans le chaos, série synthèses, Ed. Eyrolles, Coll. CEA, 1988, 351 p.

[4] Beverton R.J.H., Holt S.J., On the dynamics of exploited fish populations, Fishery Investigations, Her Majesty's stationery office, London, ser. II, vol. 19, $1957,533 \mathrm{p}$.

[5] Cushing D.H., The dependence of recruitment on parent stock in different groups of fishes, J. Cons. Int. Explor. Mer 33 (1971) 340-362.

[6] Cushing D.H., Harris J.G.K., Stock and recruitment and the problem of density-dependence, Rapp. P.-V. Réun. Cons. Perm. Int. Explor. Mer 164 (1973) 142-155.

[7] Fretwell S., Lucas H., On the territorial behavior and other factors influencing habitat distribution in birds, Acta Biotheor. 19 (1970) 16-36.

[8] Hanski I., Metapopulation dynamics: bricf history and conceptual domain, Biol. J. Linn. Soc. 42 (1991) 3-16.

[9] Hanski I., Zhang D.Y., Migration, metapopulation dynamics and fugitive co-existence, J. Theor. Biol. 163 (1993) 491-504.

[10] Hassell M.P., Comins H.N., May R.M., Spatial structure and chaos in insect population dynamics, Nature 353 (1991) 255-258.

[11] Hassell M.P., Comins H.N., May R.M., Species coexistence and self-organising spatial dynamics, Nature 370 (1994) 290-292.

[12] Hastings A., Structured models of metapopulation dynamics, Biol. J. Linn. Soc. 42 (1991) 57-71.

[13] Koslow J.A., Thompson K.R., Silvert W., Recruitment to northwest Atlantic cod (Gadus morhua) and haddock (Melanogrammus aeglefinus) stocks: influence of stock size and climate, Can. J. Fish. Aquat. Sci. 44 (1987) 26-39.

[14] Krebs C.J., Two paradigms of population regulation, Wildl. Ecol. 22 (1995) 1-10.

[15] Laevastu T., Marine climate, weather and fisheries, Fishing News Books, Oxford, 1993, 204 p.

[16] MacCall A.D., Dynamic geography of marine fish populations, Washington Sea Grant, 1990, 153 p.

[17] May R.M., Biological populations with nonoverlapping generations: stable points, stable cycles, and chaos, Science 186 (1974) 645-647.
[18] Myers A.R., Is fish recruitment related to spawner abundance? Fish. Bull. 94 (1996) 707-724.

[19] Myers R.A, Barrowman N.J., Hutchings J.A., Rosenberg A.A., Population dynamics of exploited fish stocks at low population levels, Science 269 (1995) 11061108.

[20] Murray J.D., Spatial dispersal of species, Trends Res. Ecol. Env. 3 (1988) 307-309.

[21] Potts G.W., Wootton R.J., Fish reproduction. Strategies and tactics, Academic Press, 1984, 410 p.

[22] Reeve J.D., Environmental variability, migration, and persistence in host-parasitoid models, Am. Nat. 132 (1988) 810-836.

[23] Ray C., Hastings A., Density dependence: Are we searching at the wrong spatial scale? J. Anim. Ecol. 65 (1996) 556-566.

[24] Ricker W.E., Stock and recruitment, J. Fish. Res. Board Can. 11 (1954) 559-623.

[25] Rohani P., May R.M., Hassell M.P., Metapopulations and Equilibrium Stability: The effects of spatial structure, J. Theor. Biol. 181 (1996) 97-109.

[26] Ruxton G.D., Synchronisation between individuals and the dynamics of linked populations, J. Theor. Biol. 183 (1996) 47-54.

[27] Ruxton G.D., Density-dependent migration and stability in a system of linked populations, Bull. Math. Biol. 58 (1996) 643-660.

[28] Shepherd J.G., A versatilc new stock-recruitment relationship for fisheries, and the construction of sustainable yield curves, J. Cons. Int. Explor. Mer 40 (1982) 67-75.

[29] Smith S.J., Hunt J.J., Rivard D., Risk evaluation and biological reference points for fisheries management, Can. Spec. Publ. Fish. Aquat. Sci. 120 (1993) 442 p.

[30] Solé R.V., Valls J., Bascompte J., Stability and complexity in spatially extended two-species competition, J. Theor. Biol. 159 (1992) 469-480.

[31] Turchin P., Rarity of density dependence or population regulation with lags? Nature 344 (1990) 660-663.

[32] Williams G.P., Chaos Theory Tamed, Taylor \& Francis, $1997,499 \mathrm{p}$.

[33] Wilson J.A, French J., Kleban P., McKay S.R., Townsend R., Chaotic dynamics in a multiple species fishery: a model of community predation, Ecol. Model. 58 (1991) 303-322.

[34] Wooster W.S., Bailey K.M., Recruitment marine fishes revisited, in: Beamish R.J., McFarlane G.A. (Eds.), Effects of ocean variability on recruitment and an evaluation of parameters used in stock assessment models, Can. Spec. Publ. Fish. Aquat. Sci. 108 (1989) 153-159. 


\section{APPENDIX 1}

Ricker's stock-recruitment model [24] attempts to describe the quantity of recruitment that is produced by the parental stock. His formulation produces a domeshaped curve. Ricker's stock-recruitment relationship has the following mathematical formulation:

$$
R=\alpha S \exp ^{(-\beta S)}
$$

where

$R$ is the number of recruits,

$S$ is the size of the stock of genitors (number of genitors),

$\alpha$ is the density-independent probability of survival,

$\beta$ is the coefficient of density-dependent mortality.

When $R$ and $S$ are in the same units, the equilibrium $S_{r}$ is determined by solving the equation:

$$
\begin{gathered}
S_{r}=\alpha S_{r} \exp \left(-\beta \times S_{r}\right) \\
S_{r}=\frac{\log _{e}(\alpha)}{\beta}
\end{gathered}
$$

By introducing the parameters $S_{r}$ and

$$
a=S_{r} \beta=\log _{e}(\alpha)
$$

the stock recruitment Ricker's equation becomes:

$$
R=S \exp \left(a\left(1-\frac{S}{S_{r}}\right)\right)
$$

\section{APPENDIX 2}

A defining feature of chaos is the sensitive dependence upon initial conditions. This feature is quantified by the Lyapunov's exponent $[2,3,32]$. These values are the long time average exponential rates of divergence or convergence of nearby states. If a system has at least one positive Lyapunov's exponent, then the system is chaotic: the larger the positive exponent, the more chaotic the system or in other words, the shorter the time scale of system predictability. To confirm chaos, it is necessary to confirm that the dominant exponent is positive. Lyapunov's exponents are calculated using the software Santis.

Given the time series $X(t)$ (which correspond to the values obtained by an entire simulation), a $n$-dimensional phase space is reconstructed with delay coordinates. One locates the nearest neighbour (in the Euclidean sense) to an initial point and denotes the distance between these two points $L\left(t_{0}\right)$. At a later time $t_{1}$, the initial length will have evolved to length $L^{\prime}\left(t_{1}\right)$. The
This equation is similar to the logistic equation:

$$
N_{t+1}=N_{t} e^{\left(a\left(1-\frac{N_{t}}{S_{r}}\right)\right)}
$$

The $a$ value determines whether the dynamics of the system is constant, cyclic or chaotic [17]. As $a$ increases above 2 , the solution of the equation becomes unstable and forks into a pair of points, between which the population oscillates in a 2-point cycle. This cycle of period 2 is stable for $2<a<2.526$. When increasing $a$ beyond this $(2.656>a>2.526)$, the 2-point cycle becomes unstable and each of the points forks into 2 further points. The population alternate between 4 points. As a continues to increase, population oscillates to stable cycles with 8,16 , etc. points. There is a limiting value of $a$ whereby cycles of period $2^{n}$ become unstable and bifurcate into stable cycles of period $2^{n+1}$. For $a$ below this limiting value $(a>2.692)$, the population settles into a chaotic behaviour.

\begin{tabular}{lc}
\hline Dynamical behaviour & $\begin{array}{c}\text { Value of the growth rate } \\
a\end{array}$ \\
\hline $\begin{array}{l}\text { Stable equilihrium point } \\
\text { Stable cycles of period } 2^{\mathrm{n}}\end{array}$ & $2>a>0$ \\
2-point cycle & $2.526>a>2.000$ \\
4-point cycle & $2.656>a>2.526$ \\
8-point cycle & $2.685>a>2.656$ \\
16, 32, 64, etc. & $2.692>a>2.685$ \\
Chaotic behaviour (cycles of arbitrary & $a>2.692$ \\
period, or aperiodic behaviour, depending & \\
on initial condition) & \\
\hline
\end{tabular}

Dynamics of a population described by logistic equation [17].

length element is propagated through the attractor for a time short enough so that only a small scale attractor structure is likely to be examined. One now looks for a new data point that satisfies two criteria reasonably well: its separation, $L^{\prime}\left(t_{1}\right)$, from the evolved fiducial point is small and the angular separation between the evolved and the replacement elements is small. If an adequate replacement point can not be found one retains the points which were being used. This procedure is repeated until the fiducial trajectory has traversed the entire data file, at which point one estimates:

$$
\lambda=\frac{1}{t_{M}-t_{0}} \sum_{k=1}^{N} \log _{2}\left(\frac{L^{\prime}\left(t_{k}\right)}{L\left(t_{k-1}\right)}\right)
$$

where $M$ is the total number of replacements steps. In this fixed evolution time algorithm the time step $\Delta=t_{k}-t_{k-1}$ (evolution time in parameters) between replacements is held constant. 